\title{
Publisher Correction: Non- tuberculous Mycobacteria isolated from Pulmonary samples in sub- Saharan Africa - A Systematic Review and Meta Analyses
}

\author{
Catherine Okoi ${ }^{1}$, Suzanne T. B. Anderson ${ }^{2}$, Martin Antonio ${ }^{1,3,4}$, Sarah N. Mulwa ${ }^{5}$, \\ Florian Gehre ${ }^{1,6}$ \& Ifedayo M. O. Adetifa $\mathbb{1}^{7,8,9}$
}

Correction to: Scientific Reports https://doi.org/10.1038/s41598-017-12175-z, published online 20 September 2017

In the original version of this Article, the authors Ifedayo M.O. Adetifa and Suzanne T.B Anderson were incorrectly indexed. This error has now been corrected.

(c) Open Access This article is licensed under a Creative Commons Attribution 4.0 International cc. License, which permits use, sharing, adaptation, distribution and reproduction in any medium or format, as long as you give appropriate credit to the original author(s) and the source, provide a link to the Creative Commons license, and indicate if changes were made. The images or other third party material in this article are included in the article's Creative Commons license, unless indicated otherwise in a credit line to the material. If material is not included in the article's Creative Commons license and your intended use is not permitted by statutory regulation or exceeds the permitted use, you will need to obtain permission directly from the copyright holder. To view a copy of this license, visit http://creativecommons.org/licenses/by/4.0/.

(C) The Author(s) 2018

\footnotetext{
${ }^{1}$ Vaccines and Immunity Theme, Medical Research Council Unit, Fajara, The Gambia. ${ }^{2}$ Clinical Services Department, Medical Research Council Unit, Fajara, The Gambia. ${ }^{3}$ Microbiology and Infection Unit, Warwick Medical School, University of Warwick, Coventry, United Kingdom. ${ }^{4}$ Faculty of Infectious and Tropical Diseases, London School of Hygiene \& Tropical Medicine, London, United Kingdom. ${ }^{5}$ Disease Control and Elimination Theme, Medical Research Council Unit The Gambia, Fajara, The Gambia. ${ }^{6}$ Institute of Tropical Medicine, Antwerp, Belgium. ${ }^{7}$ Department of Infectious Diseases Epidemiology, London School of Hygiene and Tropical Medicine, London, United Kingdom. ${ }^{8}$ Epidemiology and Demography Department, KEMRI-Wellcome Trust Research Programme, Kilifi, Kenya. ${ }^{9} \mathrm{College}$ of Medicine University of Lagos, Lagos, Nigeria. Florian Gehre and Ifedayo M.O. Adetifa contributed equally to this work. Correspondence and requests for materials should be addressed to I.M.O.A. (email: Ifedayo.Adetifa@Ishtm. ac.uk)
} 